\title{
CONSTRUÇÃO E DESENVOLVIMENTO DA IDENTIDADE ORGANIZACIONAL: ANÁLISE DO SÍTIO WEB DE UMA ORGANIZAÇÃO
}

\author{
Rosa Maria Sobreira \\ Instituto Politécnico de Coimbra - CEIS20/UC \\ Coimbra, Portugal
}

\author{
Gorete Marques* \\ Instituto Politécnico de Leiria \\ ESTG-IPLeiria/CELGA-ILTEC \\ Leiria, Portugal
}

\begin{abstract}
Resumo: $O$ modo como as organizações se posicionam atualmente perante seus múltiplos stakeholders e a sociedade passa, necessariamente, pelo recurso a diferentes meios tecnológicos. Este artigo, de índole interdisciplinar, pretende analisar práticas semióticodiscursivas presentes na primeira página do sítio web de uma empresa portuguesa em 2011 e em 2016. Para tal, o texto baseia-se nos princípios da Comunicação Organizacional, da Linguística Sistémico-Funcional e da Semiótica Social aplicados ao Discurso Empresarial, utilizando o sistema da transitividade de Halliday (2004) e as estruturas de representação de Kress e van Leeuwen (2006) como instrumentos de análise. Com este enquadramento, procura saber como é que a empresa se representa, como se define e apresenta no tempo, em um exercício de adaptação à sua realidade contextual. Os resultados apresentados revelam uma clara evolução no modo como a empresa se representa, mas algum desequilíbrio nas dimensões que os estudos de identidade apresentam como orientadores.
\end{abstract}

Palavras chave: Comunicação Online. Representações. Identidade Organizacional.

\section{INTRODUÇÃO}

As motivações subjacentes ao presente estudo sustentam-se em dois grandes eixos, por um lado, na vontade de concretizar um trabalho interdisciplinar entre áreas - a Comunicação Organizacional e da Linguística Aplicada -que parecem distantes por serem integradas em áreas científicas distintas, mas que, na realidade, não podem deixar de ser entendidas como complementares ou mesmo interdependentes. Por outro lado, pela forma como a academia tem reagido à importância das novas tecnologias, o que vem

\footnotetext{
* Doutorada em Ciências da Comunicação, (Especialização Comunicação Institucional), pela Universidade Nova de Lisboa, Professora Adjunta do Instituto Politécnico de Coimbra nas áreas de Comunicação Estratégica, Relações Públicas, Comunicação de Marketing e Assessoria de Imprensa e membro do Grupo de Investigação da Comunicação e Jornalismo e Opinião Pública, do CEIS20, da Universidade de Coimbra. E-mail: rsobreira@esec.pt

** Doutorada em Linguística - Especialização Linguística Aplicada pela Faculdade de Letras da Universidade de Lisboa, Professora Adjunta do Instittuo Politécnico de Leiria nas áreas de Comunicação, Português Jurídico, Metodologia e Francês Empresarial e membro do centro de investigação CELGAILTEC, da Universidade de Coimbra. E-mail: gorete.marques@ipleiria.pt
}

SOBREIRA, Rosa Maria; MARQUES, Gorete. Construção e desenvolvimento da identidade organizacional: análise do sítio web de uma organização. Linguagem em (Dis)curso - LemD, Tubarão, SC, v. 18, n. 1, p. 119134, jan./abr. 2018. 
sendo objeto de reflexão (JACKSON, 2007). Ora, com este exercício de estabelecer pontes, motiva-nos também encontrar elementos que sirvam de referência orientadora, tanto para os profissionais como para formadores do domínio da comunicação organizacional, na definição de programas de ação no âmbito das temáticas abordadas, ou seja, na produção de conteúdos sobre identidade organizacional e sua disponibilização nas páginas online.

A aplicação das novas tecnologias da informação e da comunicação no âmbito da comunicação das organizações veio mudar a forma de relacionamento das organizações com os seus públicos e "stakeholders", abrindo novos horizontes e obrigando-as a inovar na busca de novas formas de relação, interação e gestão de conhecimento. Observamos, no caso concreto das organizações, o recurso a diferentes meios, como os sítios web, para mostrarem o que são, o que fazem, como o fazem, e como devem agir e provar que são as melhores no seu ramo, já que o sucesso não passa simplesmente pela questão da produtividade, da produção de produtos ou da prestação de serviços de qualidade, mas também pela forma como se posicionam perante os seus múltiplos "stakeholders" e a sociedade.

Pretendemos, com este artigo, analisar práticas discursivas verbais e visuais presentes na primeira página do sítio web de uma empresa portuguesa em 2011 e em 2016 (estudo de caso único) para perceber o que revelam as escolhas semióticas sobre a sua identidade e sobre a representação que pretende para si própria. Para tal, seguimos os princípios da Linguística Sistémico-Funcional e da Semiótica Social aplicados ao Discurso Empresarial, em concreto o sistema da transitividade de Halliday (2004) e as estruturas de representação de Kress e van Leeuwen (2006), com vista a responder à seguinte questão: o que revelam as escolhas semióticas, nos dados em análise, sobre a identidade da empresa? A análise das escolhas léxico-gramaticais e visuais permite observar como os sistemas semióticos verbais e visuais constroem determinadas dimensões da identidade organizacional revelando de que modo a empresa se representa e como se define e apresenta no tempo, num exercício de adaptação à sua realidade contextual.

\section{FUNDAMENTAÇÃO TEÓRICA E DISCUSSÃO BIBLIOGRÁFICA 2.1 IMPACTOS DAS NOVAS TECNOLOGIAS NO CONTEXTO ORGANIZACIONAL}

Em termos de propagação, nenhuma inovação tecnológica teve um período de difusão e aceitação tão curto como a internet. A título de comparação, o telefone precisou de 70 anos, a televisão de 25 anos para serem distribuídos e utilizados de forma a serem considerados objetos comuns. A internet precisou apenas de 7 anos - entre 1990 e 1997 para ser amplamente aceite (PINHO, 2002), ou seja, menos de uma década. Mas uma década com um impacto tal que Castells (2002) descreve como sendo de ruptura e que é a responsável pelo "alvoroço" tecnológico em que vivemos hoje. Esta capacidade de aceitação e penetração contribuiu, certamente, para o acelerado desenvolvimento sinergético a que assistimos e que veio impor um novo paradigma comunicacional. Este novo paradigma tem sido de tal forma valorizado, na sociedade contemporânea, que chega a ser considerado um dos raros momentos em que uma nova configuração técnica é responsabilizada pela invenção de um «novo estilo de humanidade» (FERREIRA, 2009, $\mathrm{p} 186)$. 
O desenvolvimento no âmbito da internet, no final da década de 1990, ligando e dando poder às organizações em todo o mundo, confirmou a mudança de uma sociedade, não só de massa, mas verdadeiramente "ligada" e globalizada (FUCHS, 2009; GUILLMOR, 2005; STOHL, 2001). Foi precisamente na década de 1990 que as organizações começaram a apostar em páginas online, como sinónimo de modernidade e de prestígio.

Segundo Middleberg (2001), em muitos dos casos, essa modernidade não passava de fachada e as empresas não estavam verdadeiramente preparadas para lidar com este novo meio, ou seja, esta mudança confrontou as organizações com uma inevitável falta de imaginação, liderança e de flexibilidade para se adaptar, não por falta de inteligência ou de consciência, mas simplesmente porque a velocidade da mudança foi muito grande (BUTSHI; STEYN, 2006; WAKEFIELD, 2008). No entanto, a situação rapidamente mudou e as páginas designadas de "fantasmas", sem atualizações durante meses, desapareceram tornando-se cada vez mais sofisticadas e multifuncionais.

Este desenvolvimento foi ainda mais potenciado pela evolução da Web 1.0 para a Web 2.0. A segunda foi considerada uma nova revolução, com a internet a deixar de ser considerada uma simples rede de computadores estática para se centrar na interatividade (SOBREIRA, 2013). Arriscamos dizer que esta nova dinâmica tornou a internet num elemento central da cultura organizacional, não só como ferramenta de trabalho diário do elemento humano, mas também como forma de as organizações se manifestarem sobre as suas preocupações, interesses e motivações.

São, aliás, vários os estudos que têm demonstrado a importância da internet e de sítios organizacionais como ferramentas de comunicação que são usadas para posicionar as organizações relativamente a temáticas que a opinião pública valoriza, como a responsabilidade social e corporativa e a sustentabilidade (MELÃO; LOPES, 2013; CAPRIOTI; MORENO, 2007). Neste sentido, há muito que o foco da web deixou de ser a tecnologia em si e passou para a utilização que as pessoas e as organizações fazem dessa tecnologia em termos de conceção ou produção de conteúdos para disponibilizar nessa tecnologia, enquanto sujeitos discursivos. Nas palavras de Poster (1995), a internet deixou de ser uma simples tecnologia para ser uma verdadeira extensão das organizações e dos indivíduos. Uma extensão na medida em que permite não só descobrir e inventar novas formas de conhecimento sobre ela própria, mas também ser o repositório de todo o tipo de manifestações sobre as suas atividades e os seus actores (SOBREIRA, 2013; THORNE, 2005).

Face às profundas e rápidas alterações dos contextos externos, considera-se que o conhecimento desenvolvido e apresentado a pensar em contextos locais, nacionais, estáveis, deixam de servir à organização atuante em novos contextos de natureza global, subjetiva, virtual e, até, multicultural (THORNE, 2005; HEATH, 2002; STOHL, 2001). Nesta medida, entendemos que, do ponto de vista das estratégias de comunicação das organizações, os sítios das organizações são exercícios de assertividade que procuram ser "montras" de conhecimento ou da "profissão" das organizações como descrevem Cunha et al. (2005) e Thévenet (1997). Assim, os sítios online transformam-se em plataformas de conhecimento sobre as organizações, traduzidas em declarações de missão e visão, enumeração de atributos, competências, valores, ideologias, políticas e estratégias, objetivos ou procedimentos. Transformam-se, pois, naquilo que a organização é, no presente, no que ela faz, e no que quer ser no futuro e, na perspetiva de Van Riel e 
Frobrum (2007) e Ruão (2006), naquilo que a torna singular e distinta enquanto agente social e económico.

\subsection{OS SÍTIOS ONLINE COMO MANIFESTAÇÃO DE IDENTIDADE ORGANIZACIONAL}

O fenómeno da identidade organizacional deve ser equacionado sem limitações de fronteiras, por se tratar de uma temática que implica a construção de conhecimento a partir de diferentes áreas. Só no âmbito das organizações, o conceito de identidade tem sido desenvolvido por um número crescente de investigadores através de uma variedade de disciplinas, incluindo Comportamento Organizacional, Marketing, Comunicação, Sociologia, Publicidade, Relações Públicas, e Estratégia Organizacional (BROWN; DACIN; PRATT; WHETTEN, 2006).

Independentemente das disciplinas, a identidade das organizações surge como uma questão autoreflexiva no interior da organização no sentido de captar as suas características centrais, distintivas e duradouras (RUÃO, 2006). Esta dimensão interna diz respeito ao que é percebido como sendo essencial para o que a organização é, o que a torna distinta e o que é percebido pelos seus membros como as características que mantêm e desenvolvem a ligação entre o passado e presente da organização (e presumivelmente) o seu futuro.

No entanto, a identidade organizacional possui também uma dimensão externa. Descrita como um conceito de emissão, esta dimensão diz respeito às características únicas de cada organização, que orientam a sua actuação no mercado, e que devem refletir preocupações de construção de imagem externa, ou seja, tudo aquilo que, através de uma multiplicidade de sinais, mensagens e produtos, é oriundo do emissor. É com base nesta multiplicidade de elementos que se definirá a imagem organizacional, como uma interpretação que os públicos fazem dos traços divulgados do carácter da organização (FAVEIRO, 2004; BROWN; DACIN; PRATT; WHETTEN, 2006; RUÃO, 2006). Esta interpretação assume grande relevância na medida em que se consubstanciam em dimensões estratégica para as organizações. Essas dimensões, para além da imagem, são os conceitos de posicionamento e reputação.

Analisar os processos de construção e evolução de identidade implica observar a influência de múltiplos factores, os quais são o reflexo da forma como as organizações fazem "construções"/configurações sobre si próprias, das forças extraindividuais (como os contextos sociais, os grupos de elite ou os agentes organizacionais), dos discursos organizacionais, (como narrativas, estratégias, lideranças), do discurso social e cultural (BROWN; DACIN; PRATT; WHETTEN, 2006).

Para alguns investigadores, a identidade diz, sobretudo, respeito à luta consciente para responder às seguintes questões básicas: O que sou? O que faço? Como devo agir? (ALVESSON, 2001; SVENINGSSON; ALVESSON, 2003; CARROL; LEVY, 2008; ALVESSON et al., 2008). Trata-se de responder ao como é que uma organização se descreve, enquanto persona corporativa "falante" no sentido de "orientar" a interpretação e "significação" que os "stakeholders", que lhe são pertinentes, fazem do discurso organizacional. Nesta linha de pensamento, e do ponto de vista metodológico, para se 
analisar e perceber a identidade das organizações, faz sentido incidir a atenção sobre que discurso as mesmas produzem sobre elas e nas alterações que esse discurso sofre, a fim de descobrir qual a representação que pretendem delas próprias. Assim, centraremos a análise a partir de princípios da Linguística Sistémico-Funcional e da Semiótica Social, seguindo o entendimento de Silvestre (2003, p.16), que defende que o discurso empresarial "não se refere apenas ao discurso que ocorre nas empresas, mas também ao facto de estas existirem como resultado da sua constituição em função de práticas discursivas diversas."

\subsection{AS REPRESENTAÇÕES NO QUADRO DA LSF E DA SEMIÓTICA SOCIAL}

Estudar as representações requer um referencial teórico que permita uma análise dos significados produzidos em contexto. Optámos por seguir princípios da Linguística Sistémico-Funcional, uma teoria funcional da linguagem desenvolvida por M. A. K. Halliday, que questiona de que forma o falante usa a língua e a mesma é estruturada no seu uso. A língua é, pois, vista como um sistema semântico de produção de significados que residem em padrões sistémicos de escolha (HALLIDAY, 2004, p. 23). Neste sentido, considera-se que, de entre um potencial de escolhas linguísticas, o falante de uma comunidade discursiva realiza determinadas escolhas numa determinada situação, num determinado contexto cultural e social. Essas escolhas produzem significados, dado que assim se constroem experiências, negoceiam relações e organizam mensagens com sucesso. Em suma, a linguagem serve para construir simultaneamente aspetos de experiência, de relações e de organização da mensagem e, quando um falante faz uma escolha, realiza três tipos de significado, o que nos remete para as três metafunções de Halliday: ideacional, interpessoal e textual. Estas metafunções são analisadas na oração, unidade central da léxico-gramática, visto que o texto é uma unidade semântica realizada léxico-gramaticalmente, sendo o produto das três metafunções (HALLIDAY, 1978, p. 112).

A abordagem de Halliday foi fulcral para o desenvolvimento da Semiótica Social, que, apesar de adaptar alguns conceitos da Semiótica tradicional, se distancia. Não estuda o signo abstrato e descontextualizado, mas tem em conta o seu uso motivado, com ênfase nos usos e funções sociais dos diferentes sistemas semióticos. Neste âmbito, Kress e van Leeuwen (2006, p. 15) seguem a abordagem de Halliday, como modelo e fonte para pensar sobre processos sociais e semióticos, e desenvolvem a Gramática do Design Visual (KRESS; VAN LEEUWEN, 2006, p. 20).

Estes autores propõem os significados representacional (representação do mundo), interativo (interação com os participantes) e composicional (interação com os seus elementos), que se realizam simultaneamente nas estruturas visuais, e explicitam claramente que não pretendem uma transposição direta entre as estruturas linguísticas e visuais já que nem tudo o que é realizado pelo verbal o é pelo visual ou vice-versa.

Como objetivamos estudar a representação, ou melhor, a (re)construção de experiências, centramo-nos na metafunção ideacional, para o sistema verbal, e no significado representacional, para o visual, seguindo o entendimento de multimodalidade 
descrito por Kress e van Leeuwen (2001, p. 20): "The use of several semiotic modes in the design of a semiotic product or event, together with the particular way in which these modes are combined". Em particular, utilizaremos nos textos multimodais (os sítios web) os seguintes instrumentos analíticos: (i) o sistema da transitividade e (ii) as estruturas de representação, respectivamente.

Considerando a extensão da descrição dos referidos instrumentos, procederemos a uma breve descrição geral dos mesmos. No que respeita a (i), a análise é realizada pelo sistema da transitividade na oração. Este sistema constrói o mundo da experiência através de um conjunto de seis tipos de processos (HALLIDAY, 2004, p. 170). Destes seis tipos, há três principais: (i) os processos materiais (o fazer), (ii) os processos mentais (o saber, o sentir, a consciência, o mundo interior) e (iii) os processos relacionais (relações de experiência, classificação e identificação); e três que se situam na fronteira entre diferentes tipos por partilharem características: verbais, comportamentais e existenciais. O sistema da transitividade permite que se analise a inter-relação entre as categorias semânticas, entre processos (realizados pelo grupo verbal), participantes no processo (realizados por grupos nominais e sintagmas preposicionais ou não representados explicitamente) e circunstâncias associadas ao processo (realizadas por grupos adverbiais e preposicionais). Assim, quando um falante opta por um tipo de processo (o elemento que especifica o participante), representa uma determinada visão da realidade. Para exemplificar esta ideia, atente-se nos seguintes exemplos:

a) A empresa realiza projetos sustentáveis e inovadores;

b) A empresa acredita em projetos sustentáveis e inovadores;

c) A empresa é sustentável e inovadora.

As escolhas "realiza", "acredita" e "é" materializam concepções da realidade situadas no plano material, mental e relacional (processo material, mental e relacional, respectivamente). No enunciado a), observamos a representação da empresa como um ator social que age, que concretiza acções com potencial criativo e transformador, realçando a sua produtividade e dinamismo; a empresa é denominada Ator. Em b), verifica-se o realce da vertente mental cognitiva da empresa no plano dos seus princípios e valores orientadores; neste caso, o seu papel é de Experienciador. No último enunciado, há uma atribuição de qualidades da empresa que se apresentam como sólidas e imutáveis, remetendo para aspetos da sua estabilidade e fiabilidade; A empresa tem o papel de Portador de determinados atributos. Como se observa, as formas verbais permitem representar visões da realidade situadas em diferentes planos (da transformação do mundo, da cognição, da emoção, da identidade, entre outros).

Para a análise do visual, recorremos às estruturas de representação que se dividem em dois tipos: a representação narrativa e a representação conceptual. Estas estruturas subdividem-se e não são estanques pois, à semelhança do verbal, o texto visual pode ser multidimensional. A representação narrativa descreve os participantes em processos de ação ou de transformação, havendo sempre a presença de um vetor e que, de acordo com o seu tipo e número de participantes, se inclui em determinado processo. A representação concetual diz respeito à representação estática, em particular, à classificação (características) dos participantes, à sua estrutura e à sua essência, havendo lugar a diferentes tipos de processos. 
Para avançar no estudo desta realidade, centramo-nos num estudo de caso. O tipo de estudo que apresentamos enquadra-se no que a metodologia descreve como estudo de caso. Neste âmbito, pretendemos realizar um estudo de caso único (a análise da primeira página web de uma empresa) e instrumental, pois pretendemos que a análise permita compreendermos um assunto geral (STAKE, 1995, p. 39). Este pode ser descrito como uma pesquisa empírica que investiga um fenómeno contemporâneo no contexto da vida real (YIN, 2003, p. 13) e que pode ser adequada a entidades como grupos sociais, comunidades, instituições ou organizações (DUFF, 2008, p. 33-34), no âmbito da Linguística Aplicada, da Sociologia, da Antropologia, da Educação e da Ciência Política. Deste modo, o nosso estudo de caso é único, de natureza exploratória e comparativa, no sentido em que se reporta a uma empresa, em particular na sua primeira página internet a dois momentos temporais: 2011 e 2016. Com a incidência da análise sobre dois momentos temporais com um intervalo de 5 anos, pretendemos verificar a (in)existência de alterações, relevantes, tanto do ponto das escolhas verbais como das visuais, que sugiram alguma mudança na representação pretendida pela organização. E, como os sítios são processos contínuos e não estáticos (LYNCH; HORTON, 2001, 2), é fulcral datar a informação à qual se acede. Assim, para efeitos de análise de corpora, em 2011, a página foi recolhida a 10 de fevereiro, e, em 2016, a 3 de março.

O primeiro passo do estudo consistiu na recuperação dos resultados do estudo realizado por Marques (2011), a partir dos quais se procedeu à comparação dos elementos discursivos verbais e visuais entre os períodos acima referidos, considerando que a página de 2011 já não se encontra disponível online.

\section{ANÁLISE E DISCUSSÃO DOS RESULTADOS}

Numa primeira análise, observámos a semelhança na estrutura de cada uma das primeiras páginas dos sítios web (quadro 1):

\section{Quadro 1 - Comparação da estrutura das páginas}

\begin{tabular}{|c|c|}
\hline \multicolumn{2}{|c|}{$1^{\text {a } \text { Página }}$} \\
\hline 2011 & 2014 \\
\hline$\underline{\text { Link para: }}$ & $\underline{\text { Link para: }}$ \\
. Empresa & . Empresa \\
. Produção & . Produção \\
. Obra & . Projectos \\
. Contactos & . Notícias \\
& . Contactos \\
\hline
\end{tabular}

Numa segunda fase, observámos a existência de uma discrepância no que respeita à quantidade de informação na $1 .^{\text {a }}$ página, como se resume no quadro 2 : 
Quadro 2 - Comparação da quantidade de informação nas páginas

\begin{tabular}{|c|c|}
\hline \multicolumn{2}{|l|}{ DISCREPÂNCIA } \\
\hline 2011 & 2014 \\
\hline .1 texto com 62 palavras & $\begin{array}{l}\text { 1. }{ }^{\circ} \text { texto com } 92 \text { palavras } \\
\text { Notícias: início e link para notícias } \\
\text { Fotos de projetos } \\
\text { Mapa com os mercados } \\
\text { 2. } .^{\circ} \text { texto com } 50 \text { palavras } \\
\text {. Números (área coberta, capacidade de produção, colaboradores, expansão). }\end{array}$ \\
\hline
\end{tabular}

Para além da quantidade de informação, a diferença entre as páginas reside também no tipo de página: a primeira é estática enquanto a segunda é dinâmica. Também realçamos o facto de a página de 2016 já conter a tradução da informação em Inglês e em Francês, o que revela, naturalmente, interesse na internacionalização. Cingindo-nos ao foco desta investigação, interessa observar se o discurso entre as páginas se mantém ou se existem diferentes escolhas léxico-gramaticais e visuais. Como tal, não se apresenta uma análise exaustiva: observa-se apenas a inclusão/exclusão da empresa e o tipo de representação (visual) e de processos utilizados (verbal).

$\mathrm{Na}$ primeira página de 2011, a empresa não é apresentada verbalmente como participante, conforme se pode observar no texto:

\begin{abstract}
Actualmente, as grandes construções exigem uma execução mais rápida, estruturas mais leves e versáteis.

As interpretações arquitectónicas trazem novas formas volumétricas e os prazos de execução são cada vez mais curtos. Neste quadro a construção metálica e/ou mista (betão/aço) apresenta-se como mais vantajosa a todos os níveis.
\end{abstract}

A sua grande versatibilidade e a incorporação de menor mão-de-obra torna-a uma opção cada vez mais frequente. (ELECTROFER, 2011)

Verifica-se aqui o recurso a nominalizações (e.g. as grandes construções; as interpretações arquitectónicas), pelo que não se representa o envolvimento humano, ou melhor, são conferidas qualidades humanas a entidades abstratas. Decorrente das nominalizações, verifica-se um predomínio de processos relacionais (e.g. "A construção metálica e/ou mista (betão/aço) apresenta-se como mais vantajosa.") e de processos materiais (e.g. "As interpretações arquitectónicas trazem novas formas volumétricas.") e de um processo mental ("As grandes construções exigem uma execução mais rápida, estruturas mais leves e versáteis."). Os primeiros participantes das orações remetem para a Construção, excluindo-se a representação verbal da empresa. Que implicações têm estas escolhas?

Observe-se o seguinte enunciado: "As grandes construções exigem uma execução mais rápida, estruturas mais leves e versáteis." Em primeiro lugar, as construções surgem com consciência, seguidas de uma nominalização "execução". Ora, o produtor do texto poderia manter o mesmo participante, incluindo a empresa em enunciados como:

a) as grandes construções exigem que executemos o trabalho rapidamente;

b) ... exigem que a [nome da empresa] execute ou 
c) ... exigem que a nossa empresa execute.

Mais, o produtor do texto poderia dar primazia à empresa, colocando-a como primeiro participante:

d) nós desenvolvemos grandes construções... ou

e) a [nome da empresa] desenvolve grandes construções... .

Se assim fosse, a empresa seria incluída como Actor visto o processo ser material (de ação, fazer). No entanto, todo o texto está construído por nominalizações. É uma escolha que implica uma organização do texto em termos de ideias (EGGINS, 2004, p. 95) e não em termos de nós próprios. O uso de nominalizações permite a construção de um discurso objectivo que, pela sua natureza, se associa ao discurso técnico-científico (THOMPSON, 2004, p. 230) e que apresenta dados adquiridos objetivos. Também, de acordo com Halliday (2004, p. 657), esta escolha do uso de nominalizações remete para um discurso especialista, passando a ser uma marca de poder ou de prestígio.

Quanto ao tex to visual, a página apresenta o logótipo seguido da fotografia de parte de uma ponte moderna. Trata-se, neste caso, de uma representação concetual, de acordo com a Gramática do Design Visual. A representação concetual subdivide-se em três tipos, de acordo com as características do texto visual. Neste caso, encontramos uma estrutura de Parte-Todo, o que se encaixa na representação analítica. Como a fotografia permite que se veja parte de uma construção metálica, situamo-nos numa representação parcial do elemento, integrando-se na representação analítica inclusiva. Especificando, entendemos que a construção metálica faz parte de um Todo. É, pois, um Atributo Possessivo (que, por não estar totalmente representado, é inclusivo) que pertence ao Todo, ao Portador. Neste caso, o Portador é empresa, representado pelo seu logótipo.

No conjunto da primeira página, que relações são estabelecidas entre o verbal e o visual? Em ambos os textos o principal participante é a construção, os processos e os materiais utilizados. São as obras que "exigem" enquanto a empresa não está representada. No visual, repete-se a ideia de inovação, pela estrutura metálica, mas a empresa está presente como Portador.

Em termos de relações intersemióticas, concluímos que se verificam relações de complementaridade de significado que se realizam ao nível da expansão de significado. Em concreto, o texto verbal expande o visual em termos de significados.

No que respeita ao novo sítio, em termos gerais, observa-se, ao contrário do sítio anterior, a presença da empresa no texto verbal. Não obstante, verificam-se nominalizações cujo impacto na representação foi enunciado anteriormente, as quais, à semelhança da página de 2011, enfatizam a Construção. Na página, disponível em $<$ http://www.electrofer.pt/pt/>1, a empresa é representada verbalmente de formas distintas: (i) logo no início, no slogan em destaque, na desinência da 1. ${ }^{a}$ pessoa do plural, com projeção no futuro ("Estamos no futuro"); (ii) através do seu nome associado à terceira pessoal do singular ("Electrofer percorreu os últimos 30 anos”); (iii) também, ao incluir o cliente como participante, se inclui, pelo uso do pronome pessoal: "Conheça agora o que nos trouxe até aqui"; (iv) como segundo participante pós-modificador em "tornaram as soluções Electrofer". Estas escolhas de inclusão de participante refletem representações diferentes, nomeadamente em termos de inclusão do traço semântico

\footnotetext{
${ }^{1}$ http://www.electrofer.pt/ (acedido em 22/01/2018).
} 
"humano". Com efeito, no primeiro caso, a empresa é um participante humano, mas não se encontra materializado visto haver uma elipse do pronome pessoal sujeito. Note-se igualmente que, ao contrário do sítio de 2011, observa-se o estabelecer de relação com o público "Conheça agora o que nos trouxe até aqui".

Salienta-se ainda que, entre o slogan e o restante texto, há uma discrepância de projeção futuro-passado, pois, no slogan, o participante projeta-se para o futuro ("Estamos no futuro"), como Portador, mas, no texto, remete para a experiência acumulada ao longo dos anos, como Ator ("Electrofer percorreu os últimos 30 anos desenhando soluções chave-na-mão").

No que respeita ao conteúdo seguinte, "NOTÍCIAS", procedeu-se à análise geral do que se encontra visível nesta primeira página (os destaques). Nestas notícias, relacionadas com obras/parcerias internacionais, a empresa surge também com o seu nome, sujeito na 3. a pessoa do singular, tendencialmente como Ator de processos materiais. Na 1. ${ }^{a}$ notícia, podemos afirmar que existe uma complementaridade de processos entre visual e verbal no sentido em que há um processo material ("Fábrica de papel Venezuela" "A Electrofer ganhou concurso para fábrica de papel na Venezuela") repetido ("A Electrofer ganhou o concurso para obra de construção [...]" e no visual há uma representação narrativa (num estaleiro, encontram-se pessoas, material de construção, um camião e uma grua). Distinguem-se no sentido em que na fotografia é dada total ênfase à Meta (o participante a quem é dirigida a ação), ou seja, os elementos relativos à construção, com menor enfoque nos humanos, enquanto no verbal essa ênfase é partilhada entre empresa e obra.

$\mathrm{Na} 2$. $^{\mathrm{a}}$ notícia, em termos visuais, observa-se uma fotografia com uma paisagem correspondente a um grande rio e às suas margens. Trata-se de uma representação concetual simbólica. Associada ao texto verbal, corresponde ao complemento circunstancial de lugar. No texto verbal, o local descrito é extendido a "Serra Leoa", funcionando como complemento e como principal participante. No entanto, aí, a empresa está representada como Portador num processo Relacional Circunstancial ("está em consórcio"): "Consórcio Electrofer/MSF" "Pontes metálicas em Serra Leoa" "Para o concurso da construção de pontes metálicas em Serra Leoa, a Electrofer está em consórcio com a MSF [...]".

Na última notícia, observa-se uma imagem onde se destacam prédios. É uma estrutura narrativa que, à semelhança da primeira fotografia, tem ações constituídas pelos vetores e pelas Metas que decorrem sem que se saiba quem ou o que as desencadeou. Neste caso, a Meta é o que no texto verbal é "soluções habitacionais" e "habitações modulares". Verbalmente há a presença da empresa como Ator ("A Electrofer acaba de estabelecer protocolos [...]").

É importante salientar que as fotografias em questão devem ser encaradas como uma representação complexa no sentido em que, por um lado, se pode analisar individualmente a fotografia apenas na sua relação com o texto verbal, ou, por outro lado, se pode considerar o logótipo da empresa, mesmo sem se proceder a uma análise da metafunção textual. Com efeito, este último entendimento compreende o conjunto como uma unidade visto que o logótipo da empresa permanece no topo da página web, mesmo quando se percorre o sítio no sentido vertical.

Quanto aos "PROJECTOS", representados por fotografias de obras realizadas, observamos uma representação concetual analítica inclusiva para todos os casos, i.e., incidência nos Atributos. A representação deste tipo caracteriza-se pela ausência, 
nomeadamente, de vectores ou de simetria composicional, que Kress e van Leeuwen (2006, p. 91) entendem ser a opção mais elementar do sistema de representação visual (KRESS; VAN LEEUWEN, 2006, p. 91). Considerando a estrutura de Parte-Todo, relembra-se a presença recorrente do logótipo da empresa, que funcionou como Portador, e dos Atributos da empresa, representados pelas obras em construção e já realizadas.

Para além da presença do logótipo, que se mantém presente ao longo da página dinâmica, já referido anteriormente, consideramos o elemento cor como elemento integrador da identidade da empresa. A cor é, pois, usada ideacionalmente por denotar especificamente a empresa. Pese embora este estudo não se centre no propósito do uso das cores e da tipografia, que se entendem como recursos semióticos, nem na metafunção textual, observamos a função da cor pela promoção de coesão, criando unidade entre as diferentes partes do sítio.

Na parte "MERCADOS", associado a um mapa há um texto verbal. Em termos visuais, observam-se no mapa todos os continentes e países onde a empresa está presente. A opção de representação visual corresponde a uma representação analítica, pois consideram-se os países como Atributos da empresa (o Portador). Dentro da dimensão analítica, o processo pode ser estruturado, por estar presente o Portador ou, na sua ausência, não-estruturado. No caso em análise, consideramos a presença da empresa por meio da cor (laranja), pelo que se trata de um processo analítico estruturado. Em termos verbais, verifica-se complementaridade de participantes e de processo: "A Electrofer tem presença industrial em Portugal e a sua presença global afirma-se em construções na Europa, América do Sul, Ásia e África." Em concreto, trata-se de uma complementaridade com expansão de significados, já que o mapa é mais especificador.

Com a explanação da análise, procuramos responder ao objetivo do artigo: perceber o que revelam as escolhas semióticas desta organização sobre a sua identidade presentes na primeira página da internet. Da análise realizada, verifica-se a existência de alterações, relevantes, tanto do ponto verbal como visual, que sugerem uma mudança de objetivos na representação pretendida pela organização, em termos de reforço de alguns dos traços de identidade.

Se, quando falamos de identidade, procuramos respostas para o que somos, fazemos e de como devemos agir (ALVESSON, 2001; SVENINGSSON; ALVESSON, 2003; CARROL; LEVY, 2008; ALVESSON et al., 2008), na análise da componente verbal do sítio de 2011, encontramos elementos claros para responder ao que a organização faz. É evidente: (i) o esforço de enquadramento no setor de actividade das construções metálicas e (ii) a ênfase dada a entidades abstratas ("construção", "materiais") que remetem para o seu saber fazer. No entanto, a empresa exclui-se verbalmente (não há nome, pronome ou elemento humano). Esta exclusão pode ser entendida, pelo menos, como alguma falta de assertividade do ponto de vista de uma resposta à pergunta quem é.

A análise da componente verbal de 2016 permitiu identificar elementos que apontam para uma evolução de representação. Se, por um lado, o que ela faz, ou seja a sua "profissão", segundo Téveneth (1997) ou os seus atributos, de acordo com Cunha et al. (2005) continua presente e até é reforçado, por outro, encontramos elementos explícitos de representação do quem sou. Este reforço é observável pela inclusão de elementos como o nome da empresa ("Electrofer percorreu”), pronomes pessoais "(o que nos trouxe...") e desinência da primeira pessoa do plural ("estamos no futuro"). 
Arriscamos afirmar que esta inclusão revela um esforço de se mostrar mais participante e mais ativa no seu sector de actividade por oposição a 2011.

Da análise da componente visual do sítio, concluímos que o número de imagens aumenta substancialmente de um período temporal para outro, sendo mesmo dominante relativamente ao verbal. Tal pode revelar uma estratégia do ponto de vista da representação pretendida que passe mais pela dimensão visual do que verbal. Com efeito, o predomínio da imagem pode visar reforçar a ênfase na "construção" (o que faz).

Em termos de relações intersemióticas, verifica-se, em geral, uma complementaridade de significados. Esta complementaridade identificada entre as componentes verbais e visuais permite-nos, também, confirmar que é ao domínio das "soluções de construções metálicas" que a empresa procura dar centralidade e singularidade, de acordo com o descrito por Van Riel e Frobrum (2007) e Ruão (2006).

Os argumentos usados para sustentar a centralidade são obtidos por unidades de texto como "obra feita" e a capacidade actual de se aliar a outros, ou seja, pelo que fez e pelo que faz. É neste referencial histórico que encontramos, igualmente, elementos que permitem identificar o esforço de continuidade, como descrevem Van Riel e Frobrum (2007), que estabelece a ponte entre o passado (“[...] apoiadas por 30 anos de experiência e logística em montagem, conseguem responder a desafios tão diferentes em todo o mundo.”), o presente (“[...] está em consórcio [...]”; “[...] acaba de estabelecer protocolos [...]") e o futuro ("Estamos no futuro"). As alterações encontradas parecem indicar que organização procura explorar mais as potencialidades deste meio de comunicação do ponto de comunicar os traços centrais da sua identidade. Podemos afirmar que este sítio online é um espaço para a organização se expressar, como persona corporativa, se dar a conhecer em busca de determinado posicionamento no ambiente que lhe é relevante, ou seja, é uma verdadeira "extensão" daquilo que ela é e faz, de acordo com Poster (1995). Os "exercícios" semiótico-discursivos que evidenciámos revelam que houve uma evolução da sua identidade, no espaço de quatro anos. Essa evolução é visível, sobretudo, na sua dimensão de atuação: nesse período de tempo, passa de uma empresa de dimensão local/nacional para uma empresa com dimensão global. Ao introduzir mais dinamismo, mais do que uma opção linguística, mais informação, e complementada com imagens que reforçam o texto, como a referência aos quatro continentes e a inclusão do mapa, a organização procura também um novo posicionamento e imagem. Uma organização que evolui de um posicionamento e imagem assentes na sua capacidade de actuação local ou nacional para um posicionamento que a coloque em ação num contexto globalizado.

Contudo, se, por um lado, este caso revela que houve uma evolução, no sentido em que o seu discurso se tornou mais assertivo em termos de quais os traços da sua identidade que a empresa pretende projetar, por outro, partindo da matriz orientadora dos estudos de identidade (o que sou, o que faço e como devo agir), seria de esperar que a organização fosse mais além, no discurso sobre si própria.

Como referimos anteriormente, o discurso desta organização está centrado na sua "expertise", nos seus atributos "profissionais", ou seja, assenta em variáveis de natureza factual, tanto na dimensão verbal como visual. A organização pretende projetar-se sobretudo pelo que faz. Ora, de acordo com literatura sobre identidade (ALVESSON, 2001; SVENINGSSON; ALVESSON, 2003; BROWN; DACIN; PRATT; WHETTEN, 2006; RUÃO, 2006; VAN RIEL; FROBRUM, 2007; CARROL; LEVY, 2008; 
ALVESSON et al., 2008), seria expectável encontrar, na sua expressão de identidade, também elementos da cultura organizacional não só factuais, mas também de natureza emocional, com carácter filosófico e ideológico, como a sua missão, os seus valores e princípios orientadores.

\section{CONCLUSÕES}

O impacto que o surgimento da internet teve nas organizações, nomeadamente na capacidade de gerar e divulgar conhecimento sobre as suas estratégias de ação, no sentido de se posicionarem como personas corporativas com capacidades discursivas relevantes para os contextos em que actuam, é hoje inegável.

A análise da página online desta organização permite perceber que, neste caso, e em cinco anos, (a) a organização percebeu a importância e as potencialidades que este meio oferece do ponto de vista comunicacional. Reflexo dessa evolução é o facto de ter evoluído de estática para dinâmica, tornar-se mais apelativa do ponto vista visual e mais completa do ponto de vista textual; (b) claramente este meio é usado como plataforma de expressão da sua identidade, usada para gerar conhecimento, sobretudo sobre as capacidades técnicas da organização (c) cinco anos depois é possível saber mais sobre essa identidade e as escolhas semióticas-discursivas revelam mais assertividade e mais complexidade, na forma como se representa; (d) essa evolução demonstra que, nesse período de tempo, a organização fez um esforço de desenvolver a sua identidade, tornando-a mais complexa, na forma como pretende ser percecionada (posicionamento e imagem).

No entanto, do ponto de vista das potencialidades deste meio, como plataforma de projeção de identidade organizacional, a análise das escolhas semiótico-discursivas revelam algum desequilíbrio nas dimensões que os estudos de identidade apresentam como orientadores. Este desequilíbrio faz-se sentir na medida em que a organização se apresenta sobretudo como um agente económico com capacidade técnica, descurando a dimensão social que hoje é exigida às organizações e esta discrepância pode ter repercussões nos referidos elementos estratégicos como o posicionamento e imagem.

\section{CONTRIBUTOS E LIMITAÇÕES DO ESTUDO}

Estes resultados devem, sobretudo, servir para profissionais e formadores em comunicação refletirem sobre a mais valia de abordagens de natureza multidisciplinar, no estudo dos processos comunicacionais das organizações, e sobre a forma como os objetivos de comunicação são definidos, construídos e geridos no contexto das organizações. O conhecimento e a aplicação dos princípios provenientes da Linguística Sistémico-Funcional e da Semiótica Social podem ser (a) uma preciosa ferramenta de avaliação para a qualidade do discurso e atuação organizacional, (b) um instrumento orientador para a produção de conteúdos (verbais e visuais) nos meios online, e não só, (c) um suporte director para a definição de objetivos sobre a identidade das organizações e suas ações comunicacionais. 
No que respeita às limitações identificadas, salientam-se dois aspectos: o facto de (i) esta investigação se tratar de um estudo de caso de natureza exploratória que incide apenas numa dimensão de análise da identidade (interna) e (ii) se realizar uma análise restrita a apenas a uma pequena parte dos elementos verbais e visuais que integram o sítio da organização. A identificação destas limitações permite, no entanto, a progressão da investigação. Para tal, como perspetivas futuras, pretende-se alargar o estudo: (i) à totalidade dos elementos que integram o sítio online e comparar resultados e (ii) no sentido de entender as dimensões externas da identidade desta organização. Também se objetiva estendê-lo a outras organizações com características similares e aplicar outras tipologias qualitativas, como entrevistas aos protagonistas.

\section{REFERÊNCIAS}

ALVESSON, M.; ASHCROFT, K.; THOMAS, R. Identity matters: Reflections on the construction of identity scholarship in Organizations Studies. Organization, v. 15, n. 1, p. 5-28, 2008.

ALVESSON, M. Knowledge work: Ambiguity, image and identity. Human Relations, v. 54, n. 7, p. 863886, 2001.

BROWN, T. J.; DACIN P. A; PRATT .G.; WHETTEN, D. A. Identity, intended image, construed image, and reputation: An interdisciplinary framework and suggested terminology. Journal of the Academy of Marketing Science, p. 34-99, 2006.

CARROL, B.; LEVY, L. Defaulting to management leadership, defined by what is not. Organizations Articles, v. 15, n. 1, p. 75-96, 2008.

CASTELLS, M. A. Sociedade em rede: A era da informação: Economia, sociedade e cultura. (Vol. I). Lisboa: Fundação Calouste de Gulbenkian, 2002.

CUNHA, M.P.; REGO, A.; CUNHA R.C.; CABRAL-CARDOSO, C. Manual de comportamento organizacional. Lisboa, RH: Editora, 2005.

DUFF, P. Case study research in Applied Linguistics. New York: Lawrence Erlbaum Taylor \& Francis Group, 2008.

EGGINS, S. An introduction to Systemic Functional Grammar. $2^{\text {nd }}$ ed. London/New York: Continuum, 2004.

ELECTROFER (2011). Primeira página. Disponível a 10 de fevereiro de 2011. Link não ativo.

ELECTROFER (2016). Primeira página. Disponível a 03 de março de 2016 em

<http://www.electrofer.pt/pt>

FAVEIRO, M. H. Identidade e imagem organizacional. Lisboa: Universidade Lusíada, 2004.

FERREIRA, G. B. Comunicação, media e identidade: Intersubjectividade e dinâmicas de reconhecimento nas sociedades modernas. Lisboa: Edições Colibri, 2009.

FUCHS, C. Information and communication technologies and society: A contribution to the critique of political economy of the internet. European Journal of Communication, v. 24, n. 1, p. 69-87, 2009.

HALLIDAY, M. A. K. Language as social semiotic: The social interpretation of language and meaning. London: Edward Arnold, 1978.

HALLIDAY, M. A. K. An introduction to Functional Grammar. $3^{\text {rd }}$ ed. revised by C. M. I. M. Matthiessen. London: Arnold, 2004.

HEATH, R. L. New communication technologies: An issues management point of view. Public Relations Review, v. 24, n. 3, p. 273-288, 2000.

JACKSON, M. Should emerging technologies change business communications scholarship? Journal of Business Communication, v. 44, n. 1, p. 3-12, 2007.

KRESS, G.; VAN LEEUWEN, T. Multimodal Discourse: The modes and media of contemporary communication. London: Arnold, 2001. 
KRESS, G.; VAN LEEUWEN, T. Reading images: The grammar of visual design. $2^{\text {nd }}$ ed. Oxford: Routledge, 2006.

LYNCH, P.; HORTON, S. Web Style-Guide: Basic design principles for creating Websites. $2^{\text {nd }}$ ed. New Haven: Yale University Press, 2001.

MARQUES, G. Representações na cultura empresarial: Um estudo de caso. 2011. Tese de doutoramento não publicada, Faculdade de Letras da Universidade de Lisboa.

MELÃO, N. F.; LOPES, L. A. O desempenho de websites organizacionais: Uma proposta de modelo avaliador. Gestão e Desenvolvimento, n. 21, p. 57-81, 2013.

MIDDLEBERG, D. Relaciones públicas en un mundo interconectado. Barcelona: Deusto, 2001.

PINHO, J. B. Internet como instrumento de Relações Públicas: Vantagens e limitações. 2002. Disponível em: 〈www.portal-rp.com.br>. Acesso em: 22 set. 2002.

POSTER, M. CyberDemocracy: Internet and the public sphere. 1995. Disponível em: $<$ http://se.unisa.edu.au/vc essays.html>. Acesso em: 21 jan. 2010.

RUÃO, T. Marcas e identidades. Porto: Campo de Letras, 2006.

SILVESTRE, C. Permanências e mudanças nas relações de género no discurso empresarial: das representações às práticas de chefia - um estudo de Análise Crítica do Discurso. 2003. Tese de doutoramento não publicada, Faculdade de Letras da Universidade de Lisboa.

SOBREIRA, R,. O impacto de factores de natureza tecnológica na comunicação das organizações e nas profissões da comunicação. Exedra: Revista Científica, n. 7, p. 51-62, 2013.

STOHL, C. Globalizing organizational communication. In: JABLIN, F. M.; PUTNAM, L. L. (Eds.), The new handbook of communication: Advances in theory, research and methods. Sage Publications, p. 323375,2001 .

SVENINGSSON, S.; ALVESSON, M. Managing Managerial Identities: Organizational Fragmentation, Discourse and Identity. Human Relations, v. 56, n. 10, p. 1163-1193, 2003.

THÉVENET, M. Cultura de empresa - Auditoria e mudança. Lisboa: Monitor, 1997.

THOMPSON, G. Introducing Functional Grammar. $2^{\text {nd }}$ ed. London: Edward Arnold, 2004.

THORNE, K. Designing virtual organizations? Themes and trends in political and organizational discourses. Journal of Management Development, v. 24, n. 7, p. 580-607, 2005

VAN RIEL, C. B. M.; FOMBRUM, J. Essentials of corporate communications. New York: Routledge, 2007.

WAKEFIEL, R. I. Theory of International Relations, the Internet and Activism: a Personal Reflection. Journal of Public Relations Research, v.20, n. 1, p. 138-157, 2008.

YIN, R. Case study research. $3^{\text {rd }}$ ed. London: Sage, 2003.

Recebido em: 09/05/17. Aprovado em: 12/01/18.

Title: Construction and Development of the Organizational Identity: Analysis of an Organization's Website

Authors: Rosa Maria Sobreira; Gorete Marques

Abstract: The way organizations nowadays position themselves in front of their multiple stakeholders and society necessarily implies the use of different technological means. This article of an interdisciplinary nature intend to analyze verbal and visual discursive practices present on the first page of the website of a Portuguese company in 2011 and 2016. Thereunto, the text follows the principles of Systemic Functional Linguistics and Social Semiotics applied to the Business Discourse, using the transitivity system (HALLIDAY, 2004) and the structures of representation (KRESS; VAN LEEUWEN, 2006). With this framework, the work seeks to know how the company represents itself and how this representation has evolved in time in an exercise of adaptation to its own contextual reality. The results show a clear evolution in the way the company is represented, but some imbalance in the dimensions that the studies of identity present as guiding.

Keywords: Online communication. Representations. Organizacional identity.

SOBREIRA, Rosa Maria; MARQUES, Gorete. Construção e desenvolvimento da identidade organizacional: análise do sítio web de uma organização. Linguagem em (Dis)curso - LemD, Tubarão, SC, v. 18, n. 1, p. 119134, jan./abr. 2018. 
Título: Construcción y desarrollo de la Identidad Organizacional: análisis del sitio Web de una organización

Autoras: Rosa Maria Sobreira; Gorete Marques

Resumen: El modo como las organizaciones se tienen posicionado actualmente, frente sus múltiples stakeholders y la sociedad pasa necesariamente por el recurso a diferentes medios tecnológicos. Este artículo de índole interdisciplinar pretende analizar prácticas semióticodiscursivas presentes en la portada del sitio web de una empresa portuguesa en 2011 y en 2016. Para ello, el texto se basa en los principios de la Comunicación Organizacional, de la Lingüística Sistémico-Funcional y de la Semiótica Social, aplicados al Discurso Empresarial, utilizando el sistema da transitividad de Halliday (2004) y las estructuras de representación de Kress y van Leeuwen (2006) cómo instrumentos de análisis. Con este encuadramiento, procura saber cómo la empresa se representa, cómo se define y se presenta en el tempo, en un ejercicio de adaptación a su realidad contextual. Los resultados presentados revelan una clara evolución en el modo como la empresa se representa, pero alguno desequilibrio en las dimensiones que los estudios de identidad presentan como orientadores.

Palabras clave: Comunicación en línea. Representaciones. Identidad Organizacional.

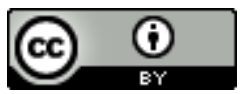

Este texto está licenciado com uma Licença Creative Commons Atribuição 4.0 Internacional.

SOBREIRA, Rosa Maria; MARQUES, Gorete. Construção e desenvolvimento da identidade organizacional: análise do sítio web de uma organização. Linguagem em (Dis)curso - LemD, Tubarão, SC, v. 18, n. 1, p. 119134, jan./abr. 2018. 